\title{
Measurement of Lightning Currents Using a Combination of Rogowski Coils and B-Dot Sensors
}

\author{
C. Romero ${ }^{*}, 1$, A. Mediano ${ }^{2}$, A. Rubinstein ${ }^{3}$, F. Rachidi ${ }^{1}$, M. Rubinstein ${ }^{3}$, M. Paolone ${ }^{1}$, \\ P. Zweiacker ${ }^{1}$, N. Mora ${ }^{1}$, D. Pavanello ${ }^{4}$ and B. Daout ${ }^{5}$ \\ ${ }^{I}$ Swiss Federal Institute of Technology (EPFL), Lausanne, Switzerland \\ ${ }^{2}$ University of Zaragoza, Spain \\ ${ }^{3}$ University of Applied Sciences of Western Switzerland, Yverdon, Switzerland \\ ${ }^{4}$ University of Applied Sciences of Western Switzerland, Sion, Switzerland \\ ${ }^{5}$ Montena EMC, Rossens, Switzerland
}

\begin{abstract}
The paper presents laboratory tests for the characterization of commercial Rogowski coils and a specially designed B-Dot sensor for the measurement of lightning currents on the Säntis telecommunications tower in Switzerland. In order to overcome the limited high frequency response of the Rogowski coils, we propose to use magnetic loops located very close to the tower. We introduce the design of a B-Dot sensor based on improvements proposed by C. E. Baum, in which the inductance is lowered by extending the vertical dimension of the loop, with the overall effect of extending the operating frequency range. To overcome the integrating behavior of the B-Dot loop when connected to lowimpedance loads (such as $50 \mathrm{Ohm}$ ), an arrangement of 100-Ohm-impedance cables connected across conicaltransmission-line gaps is used. The designed sensor is characterized by an upper frequency cutoff of $20 \mathrm{MHz}$ and a 50 $\mathrm{Ohm}$ matched termination. Simulation results and laboratory tests carried out in the high voltage laboratories of the EPFL and Montena EMC show the effectiveness of the simultaneous use of Rogowski coils and B-Dot sensors for the measurement of lightning currents.
\end{abstract}

Keywords: Lightning current, elevated struck objects, Rogowski coils, lightning current parameters.

\section{INTRODUCTION}

Lightning currents are characterized by a frequency spectrum extending from DC to a few MHz. Broadband resistive shunts (e.g. [1]) represent an ideal solution for the measurement of lightning currents as their output is a faithful reproduction of the current associated with various phases of a lightning discharge (in the case of upward discharges, i.e., the initial continuing current, superimposed pulses, and return strokes). However, such a solution is not always possible because it requires the installation of the shunt on the tower structure.

Another solution often adopted for the measurement of lightning currents on instrumented towers is the use of Rogowski coils (e.g. on the CN Tower in Canada [2]). Rogowski coils can, in principle, have a frequency response down to the $\mathrm{Hz}$ or even $\mathrm{mHz}$ region, making them suitable for the measurement of initial continuing currents associated with upward flashes (see i.e. [3]). However, their high frequency response is limited by the size of the sensor and by its resonance frequency, which might be as low as some hundreds of $\mathrm{kHz}$. As a result, the current rise time and timederivative might be affected by the high frequency shortcomings of Rogowski coils.

*Address correspondence to this author at the Swiss Federal Institute of Technology, EMC Laboratory, EPFL-SCI-STI-FR, Station, 11, CH-1015 Lausanne, Switzerland; Tel: +41 2169346 61; Fax: +41 2169346 62;

E-mail: carlos.romero@epfl.ch
In this study, we investigate the use of B-Dot sensors located in the immediate vicinity of the instrumented tower to measure the high frequency content of the lightning current, assuming proportionality between magnetic field and current. The study is carried out in the framework of the project to instrument the Säntis telecommunications tower in Switzerland, which we refer to as "the project" hereafter [4, $5]$.

The paper is organized as follows: Section 2 presents the characterization of two sets of commercial Rogowski coils purchased for the project. In Section 3, we present a specially designed B-Dot sensor with improved characteristics with respect to conventional loops used for the measurement of magnetic fields from lightning. Section 4 presents comparative laboratory testing of the Rogowski and the B-Dot sensors, and the time-domain electromagnetic simulation of the loop. Conclusions are given in Section 5.

\section{ROGOWSKI COILS AND THEIR CHARACTER- IZATION}

\subsection{Specifications of Rogowski Coils Provided by the} Manufacturers

Two sets of Rogowski coils were purchased for the project and were installed on the Säntis tower for the measurement of lightning currents. The measurements were carried out at Montena EMC Laboratories and in the high 
voltage laboratory of the Swiss Federal Institute of Technology in Lausanne.

The relevant parameters of the coils are shown on Table I. Since the Rogowski coils encircle the tower, their lengths are determined by the circumference of the tower mast at each measurement height. The coils are able to withstand current derivatives higher than $100 \mathrm{kA} / \mu \mathrm{s}$. The used coils are characterized by resonance frequencies in the order of 1 $\mathrm{MHz}$. Therefore they are equipped with a resistor placed across the coil output to damp oscillations related to the resonances.

Table 1. Specifications of the Rogowski Coils

\begin{tabular}{|c|c|c|c|c|}
\hline & $\begin{array}{l}\text { ROCOIL } \\
\text { FJ-4769 }\end{array}$ & $\begin{array}{c}\text { ROCOIL } \\
\text { FJ-4578 }\end{array}$ & $\begin{array}{c}\text { PEM } \\
\text { CWT 600x/ } \\
\mathbf{5 3 0 0}\end{array}$ & $\begin{array}{c}\text { PEM } \\
\text { CWT 600x/ } \\
11700\end{array}$ \\
\hline Length (m) & 5.3 & 11.7 & 5.3 & 11.7 \\
\hline $\begin{array}{c}\mathrm{LF}(-3 \mathrm{~dB}) \\
(\mathrm{Hz})\end{array}$ & 0.1 & 0.1 & 0.05 & 0.05 \\
\hline $\begin{array}{c}\mathrm{HF}(-3 \mathrm{~dB}) \\
(\mathrm{MHz})\end{array}$ & 1.5 & 1.0 & 2.4 & 1.0 \\
\hline $\begin{array}{l}d I / d t \text { peak } \\
(\mathrm{kA} / \mu \mathrm{s})\end{array}$ & 100 & 100 & 150 & 150 \\
\hline $\begin{array}{c}\text { Noise level } \\
m V p-p\end{array}$ & 20 & 20 & 2 & 2 \\
\hline $\begin{array}{l}\text { Sensitivity } \\
(\mathrm{kA} / \mathrm{V})\end{array}$ & $\begin{array}{c}1 \\
10\end{array}$ & $\begin{array}{c}1 \\
10\end{array}$ & 20 & 20 \\
\hline
\end{tabular}

\subsection{Evaluation of the Rogowski coils' Response}

A simple model of a Rogowski coil with its integrator is shown in Fig. (1), in which $V_{O}$ is the output voltage of the coil and $I$ is the current to be measured [6]. Note that an ideal coil produces an output signal $V_{O}$ proportional to the current derivative. An integrator is therefore added to obtain an output voltage $V_{\text {int }}$ proportional to $I$.

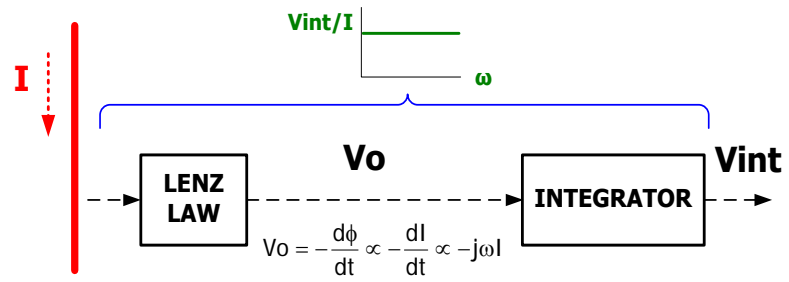

Fig. (1). Simple model of the Rogowski coil including integrator.

The output voltage $V_{\mathrm{o}}$ can be calculated as follows

$v_{o}(t)=-\frac{d \phi}{d t}=-\mu_{o} N S \frac{d i}{d t}$

and, in the frequency domain

$V_{o}=-\mu_{o} N S j \omega I$

where $N$ is the turns/length ratio and $S$ is the cross-sectional area of the coil.
The electrical model of Fig. (2) can be used to represent more accurately the response of the Rogowski coil. In that

figure, $R_{\mathrm{o}}, L_{\mathrm{o}}$ and $C_{\mathrm{o}}$ are, respectively, the resistance, the inductance and the capacitance of the coil, and $Z_{\mathrm{x}}$ is the equivalent input impedance of the integrator (including the cable connecting the coil to the integrator and the damping resistance). Typical values for the coil inductance and capacitance are $C_{0}=1.1 n F$ and $L=26 \mu \mathrm{H}$. Assuming, to a first approximation, that the input impedance of the integrator is frequency-independent, we write $Z_{\mathrm{x}}=R_{\mathrm{x}}$. Under this approximation, the frequency response of the system can be readily obtained from Fig. (2) and Equation (2) is given by

$$
\frac{V_{x}}{I}=\sqrt{\left[\frac{\frac{\omega L_{o}\left(\mu_{o} N S R_{x} \omega\right)}{1-\omega^{2} L_{o} C_{o}}}{R_{x}^{2}-\left(\frac{\omega L_{o}}{1-\omega^{2} L_{o} C_{o}}\right)^{2}}\right]^{2}+\left[\frac{\mu_{o} N S R_{x}^{2} \omega}{R_{x}^{2}-\left(\frac{\omega L_{o}}{1-\omega^{2} L_{o} C_{o}}\right)^{2}}\right]^{2}}
$$

Note that in (3), we have neglected the resistance $R_{0}$.

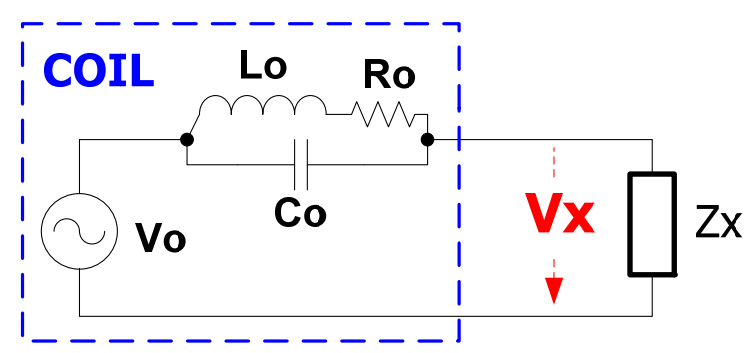

Fig. (2). Simple output model of a Rogowski coil.

The simulated response of the coil as a function of frequency and for different values of $R_{\mathrm{x}}$ is shown in Fig. (3). The same response, taking into account the presence of an integrator (assumed to be ideal), is presented in Fig. (4).

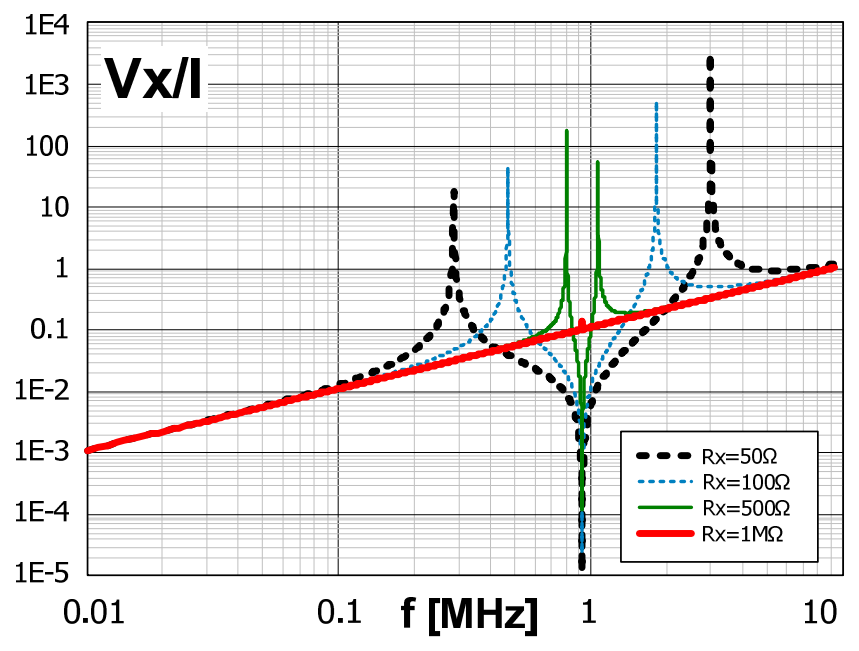

Fig. (3). Frequency response of the modeled Rogowski coil.

As can be seen on the figures, to ensure an output voltage proportional to the current derivative, the output of the coil must be connected to a high impedance. The use of long 
coaxial cables should therefore be avoided to prevent ringing when that high terminal resistance is used.

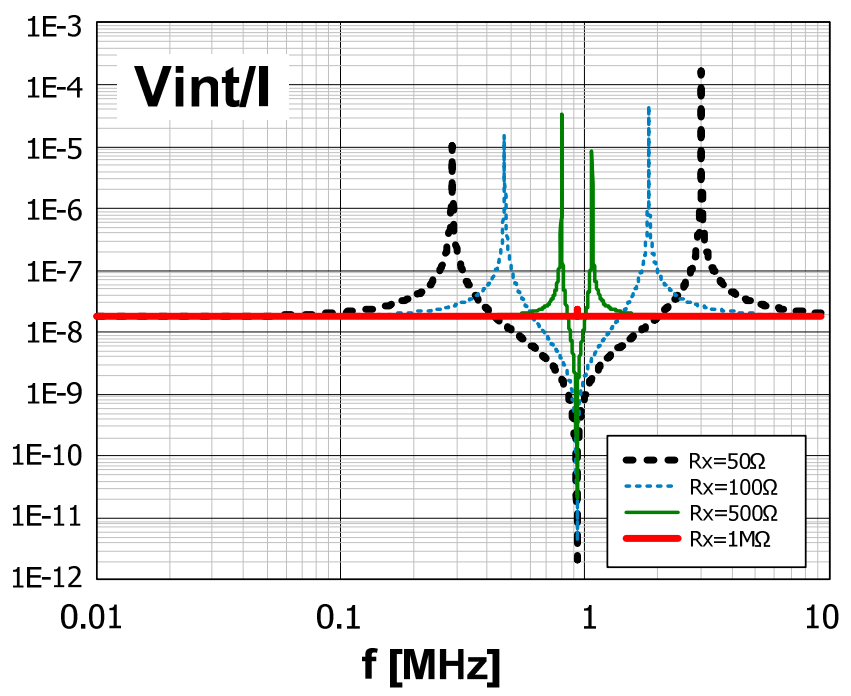

Fig. (4). Frequency response of the modeled Rogowski coil with integrator.

\section{B-DOT SENSOR}

To overcome the limited high frequency response of Rogowski coils, we propose to use magnetic loops located very close to the tower mast, at a distance from the axis of a few meters, where $d B / d t$ should be proportional to $d i / d t$ [7]. A simple loop presents some disadvantages, namely, (i) the limitation of the high-frequency response by the resonance of the magnetic loop inductance and the capacitance of the connected cable, and (ii) the need of a high-impedance termination, which might result in contamination of the waveform through multiple reflections.

\subsection{Loop Resonance Frequency}

To illustrate the limitations of a classical magnetic loop antenna, we present an analysis of the salient characteristics of a simple wire loop. The impedance of the loop can be considered to be essentially inductive. The self-inductance of a circular loop of radius $R$ is given by [8]

$$
L \cong \mu_{0} R\left(\ln \left(\frac{8 R}{r_{w}}\right)-2\right)
$$

in which $r_{\mathrm{w}}$ is the radius of the loop wire, which is assumed to be much smaller that the radius $R$ of the loop. We will consider a loop with a radius $R=14 \mathrm{~cm}$ since this value corresponds to the realized B-Dot sensor. We will use a wire radius $r_{\mathrm{w}}=1 \mathrm{~mm}$. The resulting inductance is about $473 \mathrm{nH}$. A load capacitance in the order of $500 \mathrm{pF}$ (corresponding to a 5-m long RG-58 cable) would result in a resonance frequency of about $10 \mathrm{MHz}$. Although this frequency seems high enough for lightning applications, we will see in the next section that the effect of the terminal impedance is the dominant limiting factor for the useful bandwidth of the sensor.

\subsection{Terminal Impedance}

The voltage at the output of a loop is given by
$V_{s}=\frac{Z_{\text {Load }}}{Z_{\text {Load }}+Z_{\text {Loop }}} e m f$

where $Z_{\text {Load }}$ is the load impedance, $Z_{\text {Loop }}$ is the loop impedance and emf is the electromotive force given by

$$
\text { emf }=-\frac{d \phi}{d t}
$$

in which $\phi$ is the total magnetic flux through the surface of the loop.

The output voltage of the loop is equal to the emf only when $Z_{\text {Load }} \gg Z_{\text {Loop }}$. Assuming that the loop is essentially inductive, its impedance is given by $Z_{\text {Loop }}=j \omega L$. Imposing the condition that $Z_{\text {Load }}$ should be at least ten times higher than $Z_{\text {Loop }}$, the upper frequency limit would be about $2 \mathrm{MHz}$ for the considered circular loop $\left(R=14 \mathrm{~cm}\right.$ and $\left.r_{\mathrm{w}}=1 \mathrm{~mm}\right)$ and assuming a load impedance of $50 \mathrm{ohm}$.

Time domain numerical simulations of the loop response were carried out using CST Microwave Studio ${ }^{\mathbb{R}}$ software, applying a plane wave with its magnetic field perpendicular to the loop plane and evaluating the output voltage on a 50 Ohms load in parallel with a $500 \mathrm{pF}$ capacitance representing the cable. The transient solver was set up with a sigmoidal excitation waveform of $\mathrm{DC}$ to $300 \mathrm{MHz}$ bandwidth, the steady state accuracy limit was $-50 \mathrm{~dB}$ and the upper simulation frequency was set to $2 \mathrm{GHz}$ to provide an accurate spatial discretization of the loop including the measuring gap. In Fig. (5a) we compare the frequency response of the loop obtained using an FFT routine against the ideal response (time-derivative of the magnetic field). It can be seen that the upper frequency limit of the loop is indeed about $2 \mathrm{MHz}$.

The sensor output voltage obtained from the time domain simulation was integrated and scaled to obtain the current. As done with the current derivative, an FFT routine was used to plot the ratio between the current and the integrated output of the loop is plotted against the frequency in Fig. (5b). The EM simulation shows the predicted resonance at about 10 MHz.

\subsection{Improved Design}

In $[9,10]$, Baum proposed an improved design of multigap B-Dot sensors which does not have the above-mentioned shortcomings. Specifically, the inductance is lowered by extending the vertical dimension of the loop, with the overall effect of extending the operating frequency range. To overcome the integrating behavior of the loop when connected to low-impedance loads (such as $50 \mathrm{Ohms}$ ), an arrangement of four 100-Ohm-impedance cables connected in two pairs, respectively in parallel, across conicaltransmission-line gaps [11] thus presenting a total impedance of $400 \mathrm{Ohms}$ to the loop and $50 \mathrm{Ohms}$ output impedance to the measurement equipment is proposed.

Based on Baum's studies, a sensor was designed for our purpose with a $50 \mathrm{Ohm}$ matched termination. Fig. $(\mathbf{6 a}, \mathbf{b})$ the actual sensor manufactured at the Swiss Federal Institute of Technology in Lausanne (EPFL). 
The newly designed B-Dot sensor features, in addition, a much better immunity against the electric field, compared to conventional loops, because the signal outputs from each gap pair are properly combined to eliminate the electric field components induced in the gaps as done by Baum $[9,10]$.

(a)

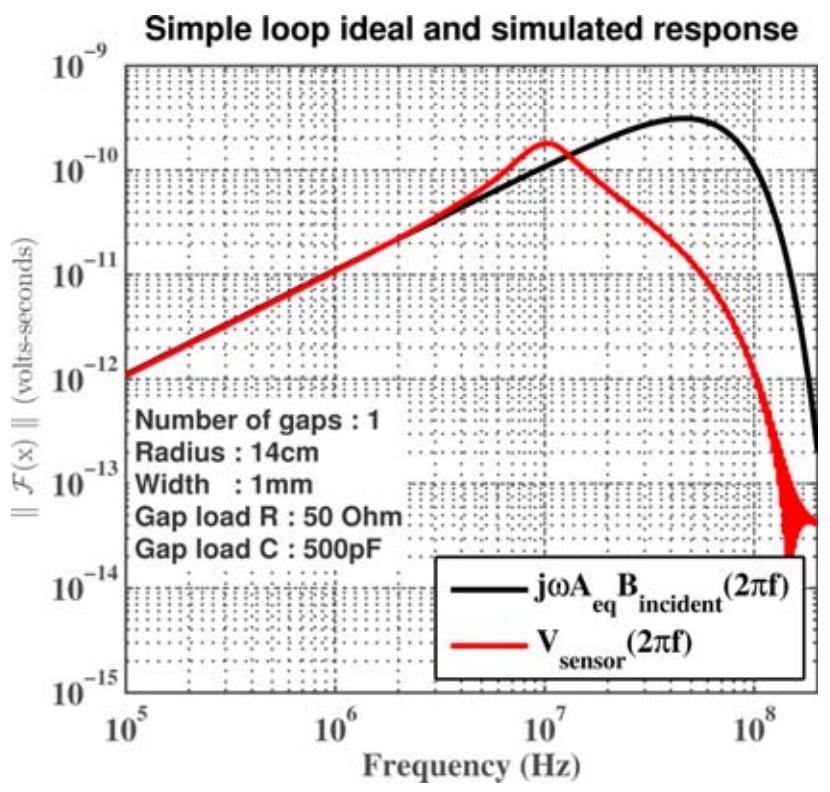

(b)

Simple Loop EM simulation: Injected-to-inferred current ratio

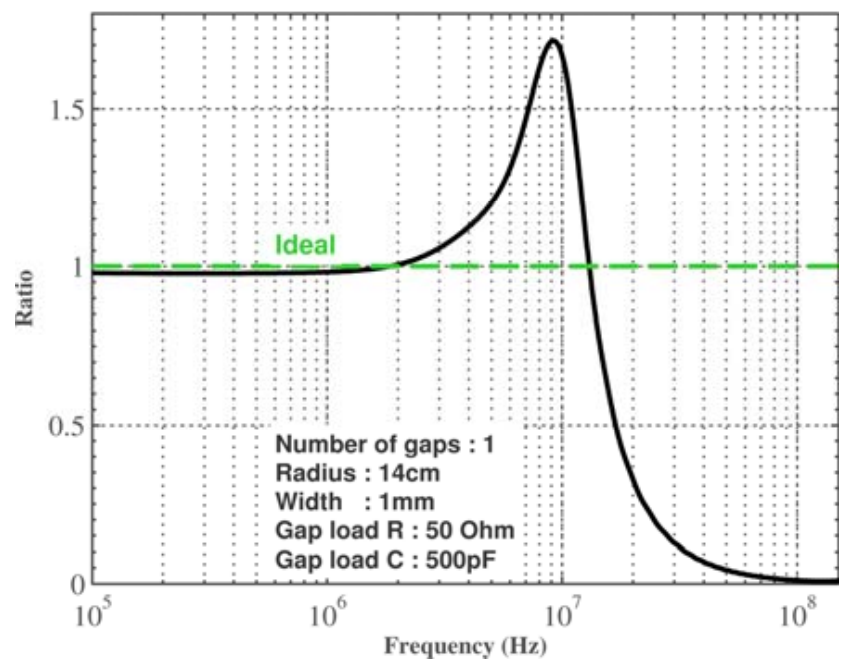

Fig. (5). (a) CST Microwave studio simulation of the simple loop. Comparison between ideal output (Equation 1.2) and simulated voltage output for the simple loop sensor. (b) Ratio between the input current and the numerically integrated and scaled simulated voltage output (inferred current) of a simple loop.

As done in the previous section for the simple loop, a time-domain simulation was carried out for the designed multi-gap loop using CST Microwave Studio ${ }^{\circledR}$ software. Fig. (7a) presents the simulated geometry along with the adopted hexahedral meshing. The same equivalent load impedance (50 Ohms and $500 \mathrm{pF}$ ) used for the simple loop was used in the simulations. Fig. (7b) presents the response of the sensor output as a function of frequency obtained using an FFT routine, and Fig. (7C) the ratio between the input current and the integrated loop output. It can be seen that the upper frequency limit of the sensor is extended up to about 10 $\mathrm{MHz}$.

(a)

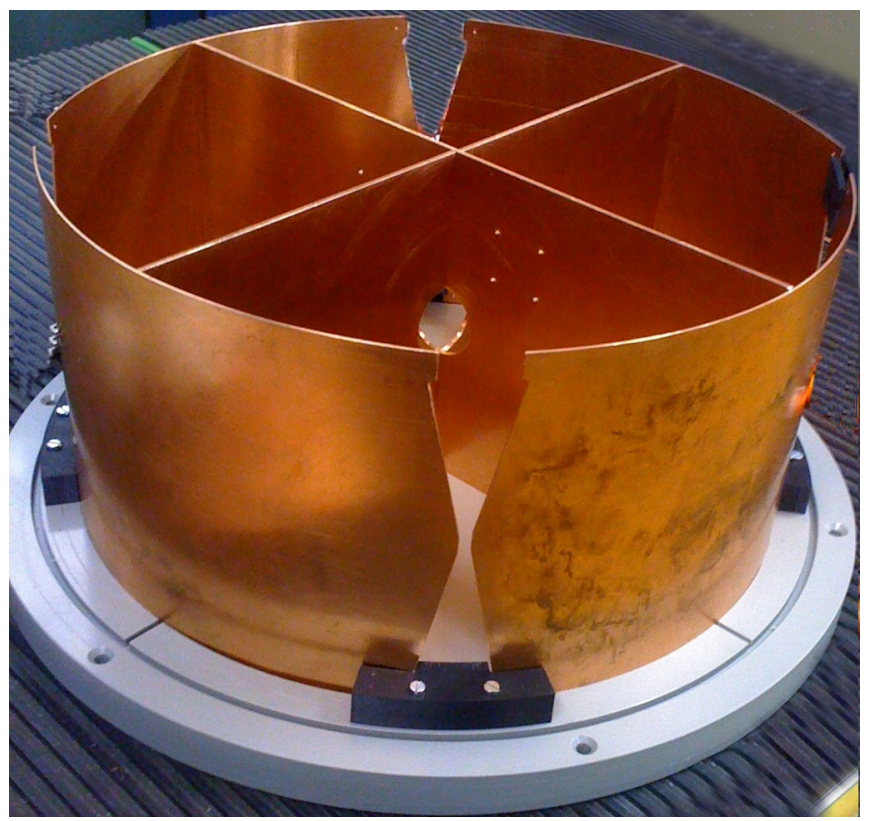

(b)

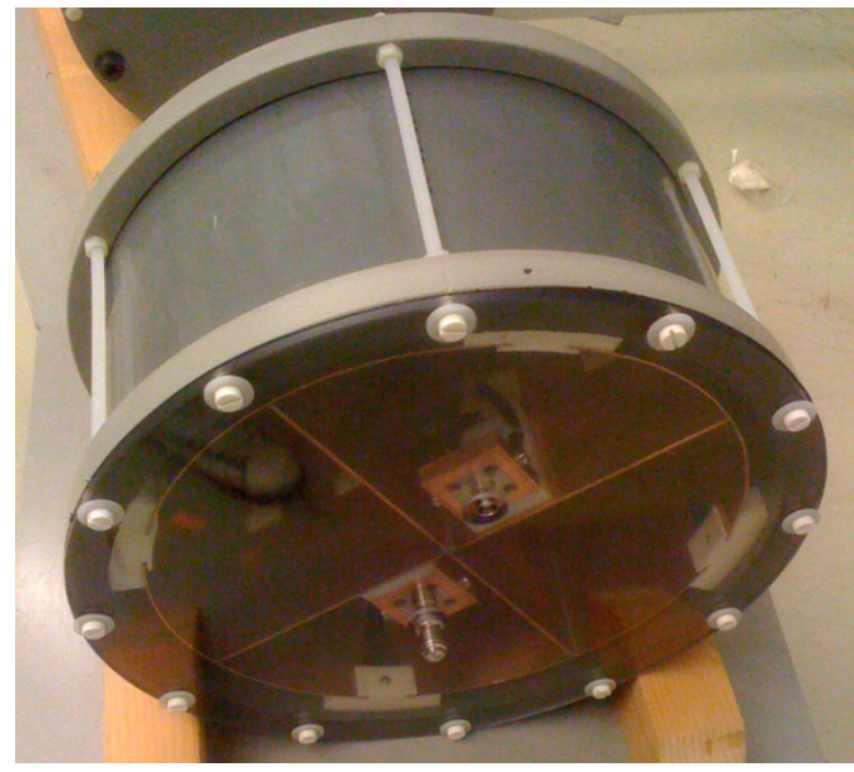

Fig. (6). (a) Detail of the conical transmission line gap. (b) Realized B-Dot sensor.

\section{LABORATORY TESTING}

Fig. (8) shows test results carried out in the high voltage laboratory of the EPFL, where an impulse current characterized by a $2.5 \mathrm{kA}$ amplitude and about $1 \mu$ s rise time was measured with a reference current sensor (Pearson Current Monitor 110) and, simultaneously, with (i) a PEM CWT 600x/5300 Rogowski coil (see specifications in 


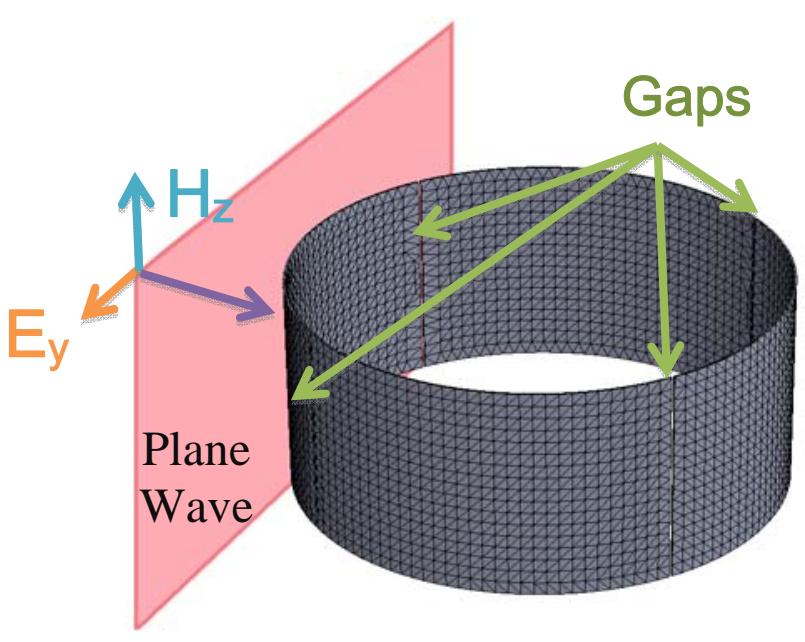

(a)

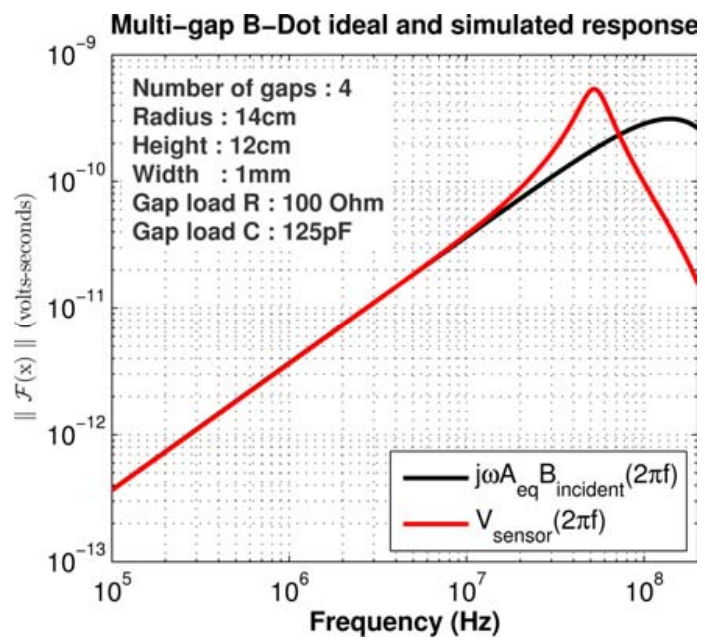

(b)

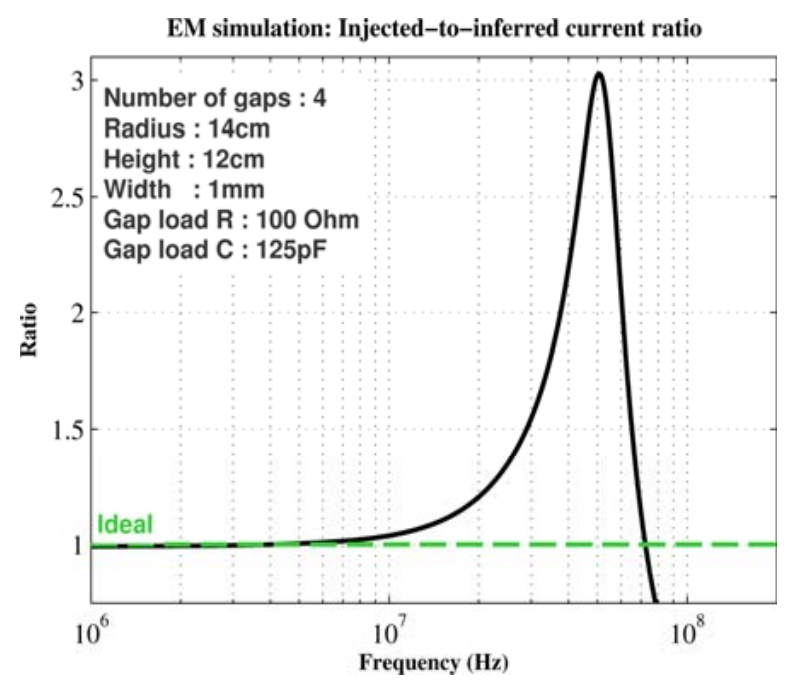

(c)

Fig. (7). (a) Simulation setup for the electromagnetic simulation showing the applied plane wave and the domain meshing details. (b) Comparison between ideal output (equation 1.2) and simulated output for the multi-gap loop. (c) Ratio between the input current and the numerically integrated and scaled simulated voltage output (inferred current) of a four-gap loop.
Table 1) and (ii) the designed B-Dot sensor (whose output was integrated numerically). The current was generated by a 1.1-MV impulse generator. The B-Dot sensor was located 2 $\mathrm{m}$ from the conductor carrying the current. It can be seen in Fig. (8) that the integrated output of the B-Dot sensor follows satisfactorily the current, while the Rogowski coil provides a good picture of the current late-time response. It can also be seen that some oscillations are present in the output of the Rogowski coil, the frequency of which is in the order of $\mathrm{MHz}$. These oscillations are essentially due to the imperfect matching of the coil output, as discussed in Sect. 3.2.

Based on the schematics in Figs. $(\mathbf{1}, \mathbf{2})$, we simulated the circuit using Spice (the Spice model block diagram is shown in Fig. (10). An input reference current is derived with respect to time and applied to the coil model. The signal out of the coil is injected into a model for the output cable and then to the integrator model. The integrated output is then low-pass filtered.

The simulation results are shown in Fig. (9) for different output cable lengths. Oscillations similar to those observed in the measurements can be seen in the simulation results. The simulations show that the oscillations are due to the presence of the 5-m long connecting cable. Reducing the cable length to $1 \mathrm{~m}$, the oscillations on the output are reduced considerably.

\section{CONCLUSIONS}

Within the project to instrument the Säntis telecommunications tower in Switzerland, we investigated the use of B-Dot sensors located in the immediate vicinity of the instrumented tower to measure the high frequency content of the lightning current, in conjunction with Rogowski coils.

It is emphasized that, for the Rogowski coils, the use of long coaxial cables should be avoided to prevent ringing.

In order to overcome the limited high frequency response of the Rogowski coils, we proposed to use magnetic loops located very close to the tower. We showed that the use of conventional loops (B-Dot sensors) might be inadequate due, on the one hand, to the limitation of their high-frequency response stemming from the resonance of the magnetic loop inductance and the capacitance of the connected cable. On the other hand, conventional loops require the use of a highimpedance termination, which might result in contamination of the waveform through multiple reflections when relatively long cables are used.

We proposed to use an improved design for the B-Dot sensor based on the works of Baum which does not have the above-mentioned shortcomings. Specifically, the inductance is lowered by extending the vertical dimension of the loop, with the overall effect of extending the operating frequency range. To overcome the integrating behavior of the loop when connected to low-impedance loads (such as $50 \mathrm{Ohm}$ ), an arrangement of 100-Ohm-impedance cables connected across conical-transmission-line gaps is proposed. The designed sensor is characterized by an upper frequency cutoff of $20 \mathrm{MHz}$ and a $50 \mathrm{Ohm}$ matched termination.

Laboratory tests carried out in the high voltage laboratory of the EPFL showed the effectiveness of the joint use of 


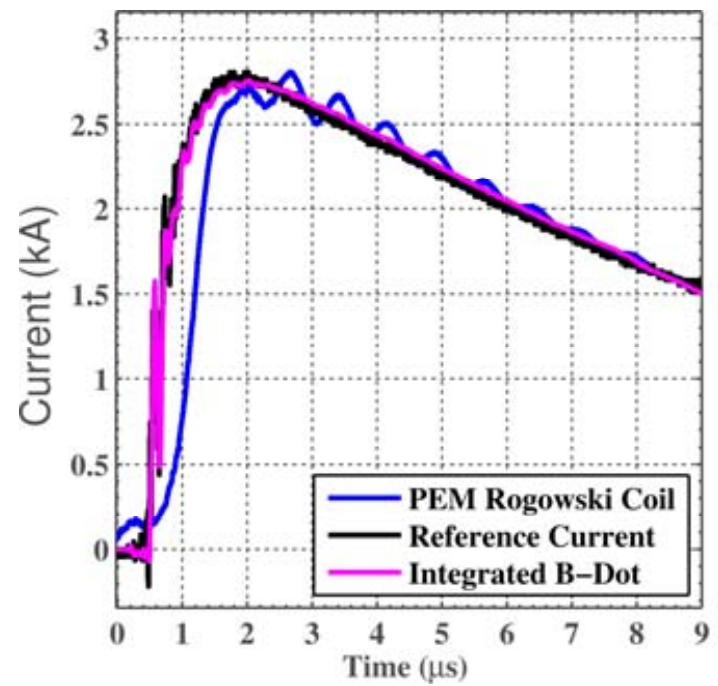

(a)

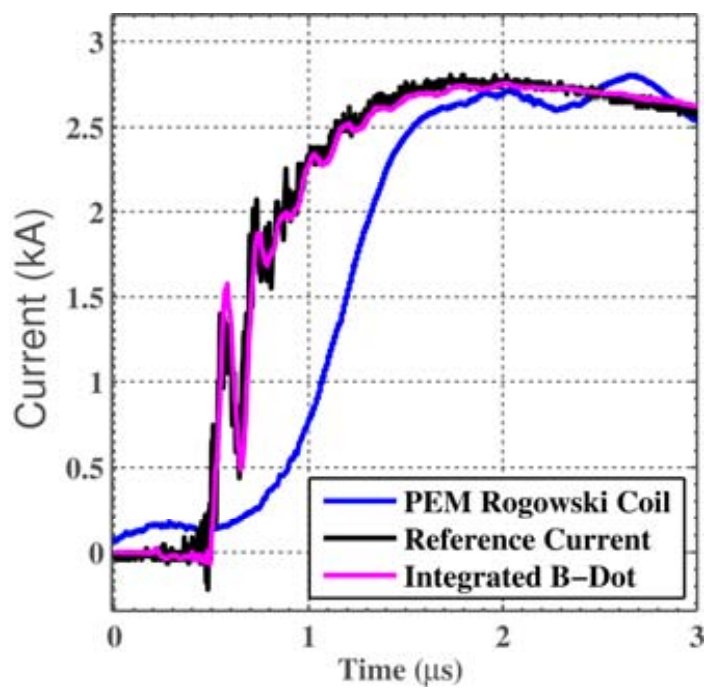

(b)

Fig. (8). Test results: (a) Comparison between the PEM Rogowski coil (blue), the integrated output of the multigap B-dot sensor (magenta) and the reference current measured with a calibrated current transformer (black). (b) Expanded view of the first 3 micrcoseconds.
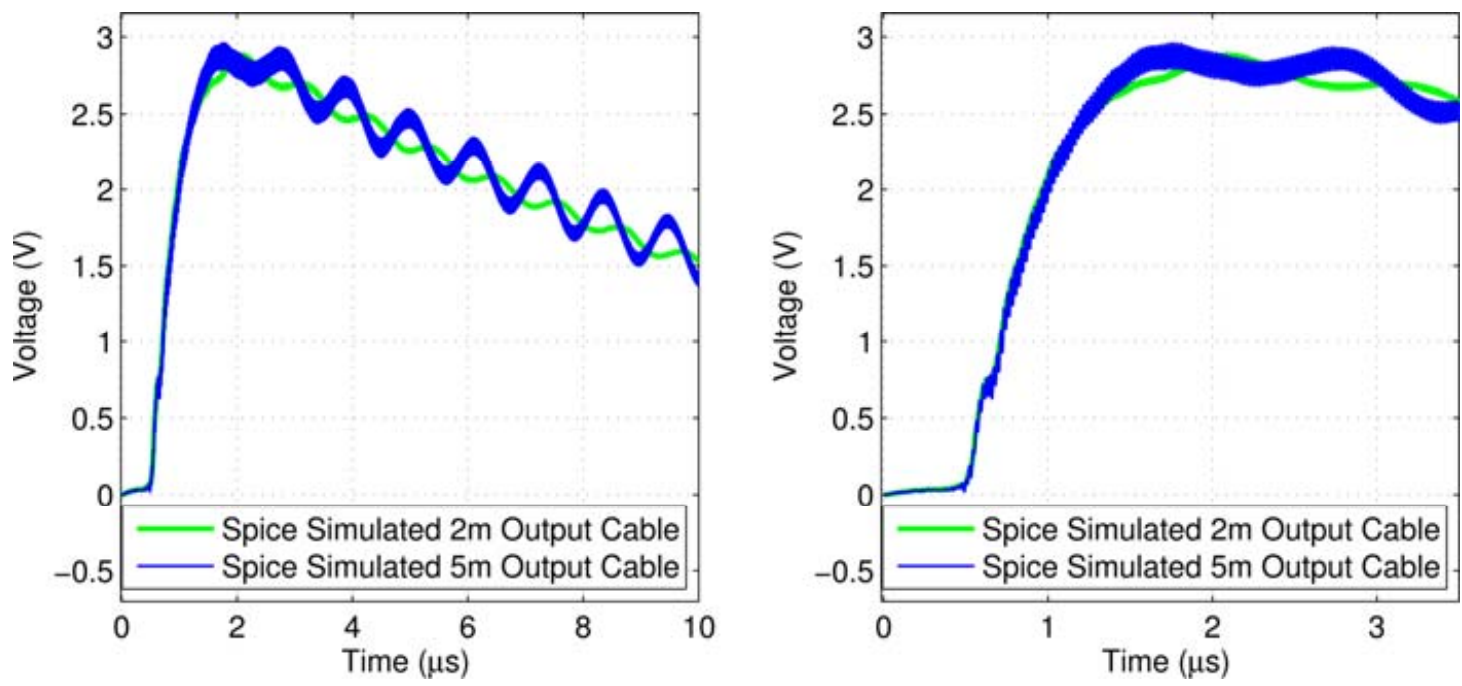

Fig. (9). Spice simulation results: two cable lengths are simulated using the derived equivalent circuit of the Rogowski coil measurement system. Simulation is able to reproduce the measured resonance of the Rogowski coils (compare with curve blue in Fig. 8).

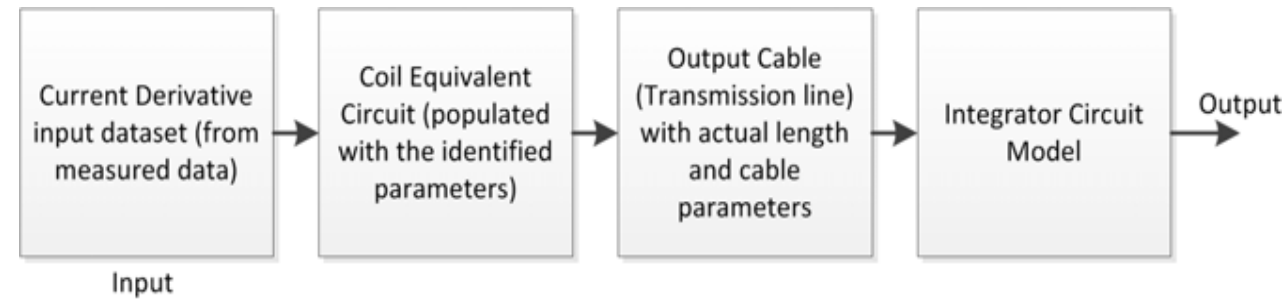

Fig. (10). Block diagram of the Spice simulation circuit.

Rogowski coils and B-Dot sensors for the measurement of lightning currents.

\section{CONFLICT OF INTEREST}

Declared none.

\section{ACKNOWLEDGEMENTS}

This work has been carried out within the framework of the European COST Action P18. Financial support from the Swiss Office for Education and Research SER (Project No. C07.0037) and the Swiss National Science Foundation (Project No. 200021-122457) are acknowledged. 


\section{REFERENCES}

[1] Diendorfer G, Pichler H, Mair M. Some parameters of negative upward initiated lightning to the gaisberg tower (2000 - 2007). IEEE Trans Electromagn Compat 2009; 51(3): 443-52.

[2] Hussein AM, Janischewskyj W, Milewski M, Shostak V, Chisholm W, Chang JS. Current waveform parameters of $\mathrm{CN}$ Tower. J Electrostat 2004; 60: 149-62.

[3] Hussein AM, Milewski M, Burnazovic E, Janischewskyj W. Current waveform characteristics of $\mathrm{cn}$ tower negative and positive lightning. $\mathrm{X}$ International Symposium on Lightning Protection (SIPDA) 2009 Nov 9-13; Brazil: Curitiba 2009; pp. 451-456.

[4] Rubinstein A, Romero C, Paolone M, et al. Lightning measurement station on Mount Säntis in Switzerland. X International Symposium on Lightning Protection (SIPDA); 2009 Nov 9-13; Brazil: Curitiba 2009

[5] Romero C, Rubinstein A, Paolone M, et al. Instrumentation of the säntis tower in switzerland for lightning current measurements. Int J Plasma Environ Sci Technol 2012; 4:79-85.
[6] Sato M, Kuramoto S, Matsuoka K, Ohta M, Takemoto K. Design of large-circle rogowski coil for measuring lightning current in building columns and girders. Electron Commun Jpn 1994; 77(10): 75-84.

[7] Rakov VA. Lightning discharges triggered using rocket-and-wire techniques. Recent Res Devel Geophys 1999; 2: 141-71.

[8] Tesche FM, Ianoz M, Karlsson T. EMC Ananlysis methods and computational models. New York: Wiley Interscience 1997.

[9] Baum CE. Maximizing frequency response of a B-DOT loop: Note 8, Sensor and Simulation Notes 1964.

[10] Baum CE, Breen EL, O’Neill JP, Giles JC, Sower GD. Sensors for electromagnetic pulse measurements both inside and away from nuclear source regions. IEEE Trans Antennas Propag 1978; 26: 2235 .

[11] Baum CE. A conical-transmission-line gap for a cylindrical loop. Sensor \& Simulation Note 42, 1967.

(C) Romero et al.; Licensee Bentham Open.

This is an open access article licensed under the terms of the Creative Commons Attribution Non-Commercial License (http://creativecommons.org/licenses/by-nc/3.0/) which permits unrestricted, non-commercial use, distribution and reproduction in any medium, provided the work is properly cited. 